\title{
Collagen stimulating factors from lung in experimental paraquat poisoning demonstrated in vitro and in vivo
}

\author{
WD THOMPSON, * RS PATRICK \\ From the University Department of Pathology, Glasgow Royal Infurmary, Castle Street, Glasgow
}

SUMMARY Collagen stimulating factors, previously described in experimental liver injury and healing skin wounds, have now been found in experimental paraquat lung injury. These factors are active not only in culture but also in vivo. The evidence from this third example of tissue injury points to an important pathological role in chronic inflammation.

Factors which stimulate collagen synthesis and collagen prolyl hydroxylase activity in cultured fibroblasts have been found previously in the healing phase following two types of experimental tissue injury. Extracts of carbon tetrachloride damaged mouse liver ${ }^{1}$ and of healing skin wounds ${ }^{2}$ were subjected to molecular sieve column chromatography and similar patterns of stimulating activity were found in column fractions from each. This paper describes the presence of collagen stimulating factors in a third type of experimental tissue damage-paraquat lung injury. Evidence is provided that such factors are active not only in culture but also in vivo.

Experimental paraquat poisoning causes the pulmonary alveolar lining epithelium to be selectively destroyed. ${ }^{3}$ The subsequent severe inflammatory reaction leads to ingrowth of fibroblasts with intraalveolar fibrosis by day $5 .^{4}$ This histological phase of increased fibroblast activity corresponds to a biochemical phase of increased collagen synthesis, detected as collagen prolyl hydroxylase activity. ${ }^{5}$ The activity of this enzyme, which has a critical function in collagen synthesis, ${ }^{6}$ was found to reach a maximum also by day 5 . Accordingly, lung tissue was taken at day 4 or 5 for detection of collagen stimulating factors.

\section{Material and methods}

Mature male Sprague-Dawley rats (average weight $300 \mathrm{~g}$ ) were given a single toxic dose of paraquat

*Present address: Department of Pathology, University Medical Buildings, Foresterhill, Aberdeen.

Accepted for publication 24 January 1984 dichloride (Sigma) in isotonic saline, $20 \mathrm{mg} / \mathrm{kg}$ body weight, by intraperitoneal injection. Test and control rats were killed at days 4 or 5 and the lungs removed promptly and placed on ice. The tissue was either used at once or stored at $-20^{\circ} \mathrm{C}$. Three grams of lung parenchyma taken from at least two rats in each experimental group was chopped with scissors and then homogenised at half speed for 1 min using a Silverson homogeniser in 5 volumes of $0.05 \mathrm{M}$ phosphate buffer, $\mathrm{pH} 7 \cdot 0$, at $4^{\circ} \mathrm{C}$. The homogenate was centrifuged at $12000 \mathrm{~g}$ for $20 \mathrm{~min}$ at $4^{\circ} \mathrm{C}$. The supernatant minus surface lipid was applied to a K16/90 column of G25 fine Sephadex (Pharmacia), bed height $85 \mathrm{~cm}$. Fractions ( 3 or $4 \mathrm{ml}$ ) were collected at a flow rate of $30 \mathrm{ml} / \mathrm{h}$ at $4^{\circ} \mathrm{C}$, and protein content was continuously monitored at $280 \mathrm{nM}$. In later experiments the supernatant was applied to Centriflo ultrafiltration cones (Amicon) of 50000 dalton exclusion and the $750 \mathrm{~g}$ filtrate obtained.

One millilitre aliquots of column fractions or buffer were added to replicate cultures of L 929 mouse fibroblasts (Gibco-Biocult, Paisley) seeded two days previously at a density of 0.6 to 0.8 million cells per $25 \mathrm{~cm}^{2}$ plastic culture flask (Nunc products). Consecutive or alternate fractions were tested depending on numbers of flasks available. The cells were grown in $5 \mathrm{ml}$ of minimum essential medium with the addition of $10 \%$ fetal calf serum, $2 \times 10^{-3} \mathrm{M}$ L-glutamine, $0.25 \times 10^{-6} \mathrm{M}$ ferric nitrate, $0.25 \times$ $10^{-3} \mathrm{M}$ sodium-L-ascorbate, $100 \mathrm{units} / \mathrm{ml}$ of penicillin, and $100 \mu \mathrm{g} / \mathrm{ml}$ of streptomycin. All media were obtained from Gibco-Biocult and chemicals were obtained from Sigma. After $4 \mathrm{~h}$ incubation the cells were assayed for prolyl hydroxylase activity ${ }^{7}$ or collagen synthesis ${ }^{8}$ as previously described. ${ }^{\prime 24}$

The assay for prolyl hydroxylase depends on the 
ability of the enzyme to convert prolyl residues in collagen to peptide bound hydroxyproline. A substrate containing $\mathrm{L}-\left[3,4-{ }^{3} \mathrm{H}\right]$ proline labelled collagen is prepared from chick embryos in the presence of $\alpha, \alpha^{1}$-dipyridyl, which inhibits hydroxylation. On hydroxylation of the labelled proline by enzyme in subsequent assay material, a hydrogen atom is released and tritiated water collected by vacuum distillation for scintillation counting. The assay for collagen polypeptide synthesis depends on the exposure of material labelled with $\mathrm{L}-\left[5-{ }^{3} \mathrm{H}\right]$ proline to bacterial collagenase free of non-specific proteolytic activity. Labelled small peptides are released and estimated by scintillation counting. Wilcoxon's sum of ranks test was used for statistical analysis.

In later experiments ultrafiltration samples were tested by intraperitoneal injection into CFLP littermate male mice using animals of similar size (20$25 \mathrm{~g}$ ) in groups of four or five. After $2 \mathrm{~h}$ the mice each received a further injection of $0 \cdot 1 \mu \mathrm{Ci}$ of $5{ }^{3} \mathrm{H}$ proline (Amersham) in $0.5 \mathrm{ml}$ normal saline in the flank. The mice were killed $4 \mathrm{~h}$ later, and the liver and sometimes the lungs as well were removed and stored at $-20^{\circ} \mathrm{C}$ for subsequent prolyl hydroxylase and collagen synthesis assays as previously described. ${ }^{5111}$ As the amount of material available for assay was greater than from tissue cultures, both assays could be readily combined. The results are expressed as DPM per 50 and $200 \mu$ l of homogenate for prolyl hydroxylase and collagen synthesis respectively, being the original data. Student's t test was used for statistical analysis.

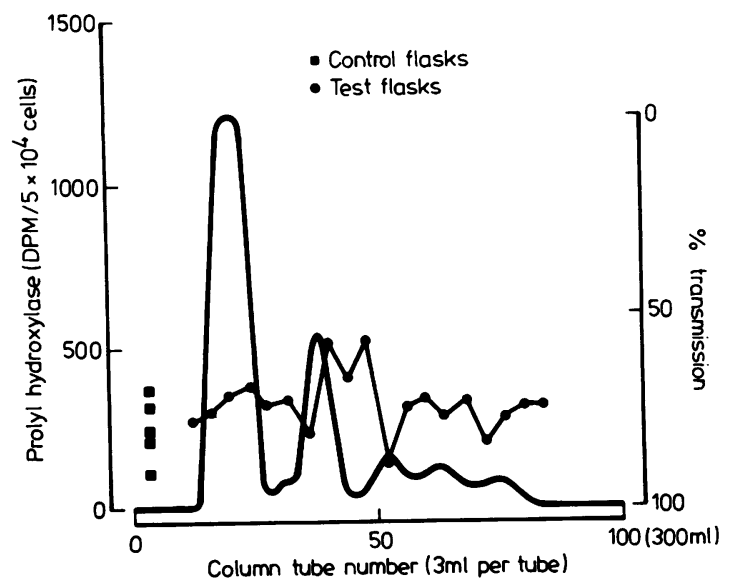

Fig. 1 Effect of G25 Sephadex column fractions from normal rat lung on prolyl hydroxylase activity of flasks of cultured L929 fibroblasts. No significant increase is seen compared with control cultures.

\section{Results}

With normal lung extract no increase in prolyl hydroxylase activity was seen in test compared with control (buffer only) fibroblast cultures and no consistent pattern was evident (Fig. 1). With paraquat lung extract, the continuous protein profile from the column was subtly different with greater prominence of later peaks (Fig. 2). A fairly consistent pattern of at least five zones of stimulation of activity in cultures was observed, only roughly corresponding to the major protein peaks. Comparison of test and control culture results by means of Wilcoxon's sum of ranks test confirmed a significant overall increase $(p<0.01)$. Fig. 3 shows a similar experiment using paraquat lung extract following storage of tissue for one week at $-20^{\circ} \mathrm{C}$. The continuous protein profile shows even greater prominence of particularly the last peak. The fibroblast cultures exposed to the later fractions show the greater stimulation. Once more, the results with the test cultures were significant compared with control (buffer only) cultures $(\mathrm{p}<0 \cdot 05)$.

Again, with normal lung extract no increase in collagen synthesis was seen in test compared with control cultures (Fig. 4). Results with this assay, however, were more erratic than for prolyl hydroxylase. With paraquat lung extract, a less consistent pattern of stimulation was obtained, and overall, the results were not significantly different (Fig. 5). Nevertheless, individual cultures achieved high values not seen using normal lung column fractions. Paraquat lung stored frozen appeared to lose much of its activity together with a change in protein profile with further enhancement of later peaks

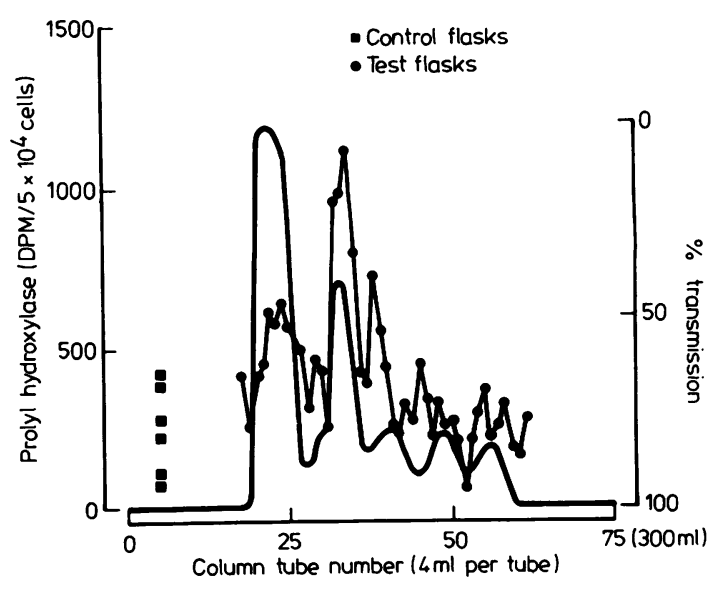

Fig. 2 Effect of comparable column fractions from paraquat damaged rat lung on prolyl hydroxylase activity of cultured fibroblasts. 


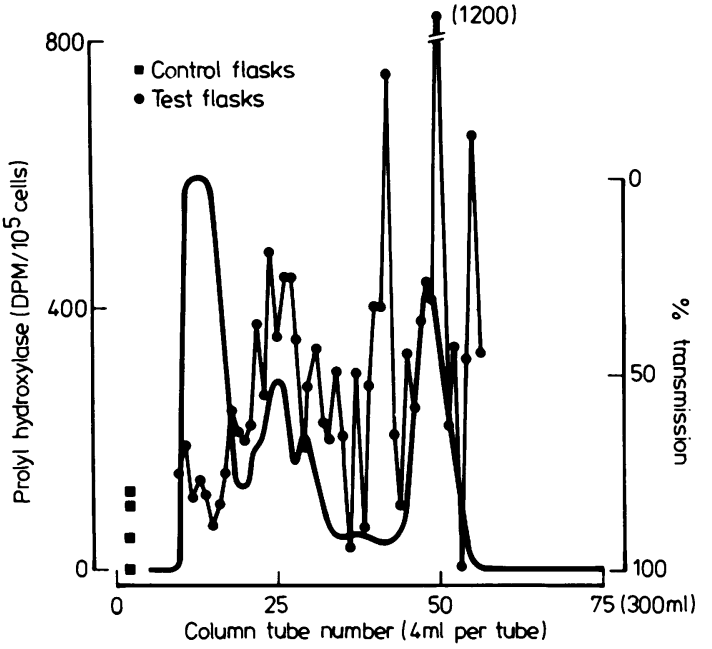

Fig. 3 A further experiment similar to Fig. 2 using paraquat lung after storage at $-20^{\circ} \mathrm{C}$.

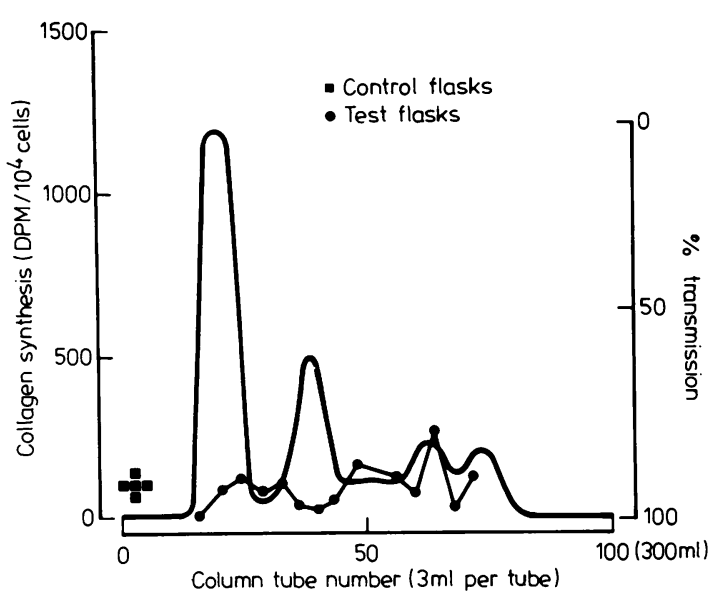

Fig. 4 Effect of column fractions from normal rat lung on collagen chain synthesis in cultured fibroblasts. No significant increase is seen compared with control cultures.

(Fig. 6). Some residual stimulatory activity appeared to persist in those lower molecular weight fractions.

Intraperitoneal injection of normal and paraquat lung extracts did not appear to distress the mice and, when killed $6 \mathrm{~h}$ later, there was no evidence of peritoneal inflammation. The injection of the appropriate isotope for the collagen chain synthesis assay did not adversely affect the assay for prolyl hydroxylase on the same tissue. The proline is label-

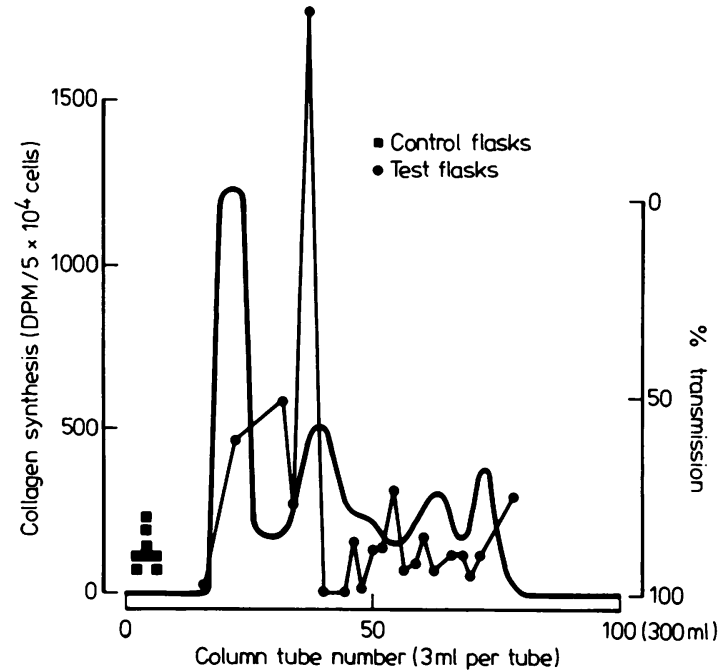

Fig. 5 Effect of column fractions from paraquat damaged rat lung on collagen synthesis in cultured fibroblasts.

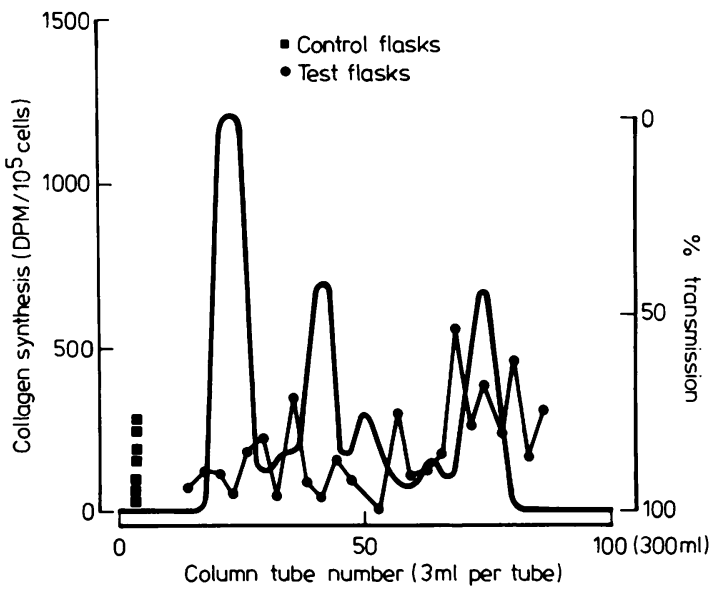

Fig. 6 A further experiment similar to Fig. 5 using the same paraquat lung after storage at $-20^{\circ} \mathrm{C}$.

led in such a position in this isotope that it is not available for release by hydroxylation.

The Table shows the effect of injection of $2 \mathrm{ml}$ of either normal or paraquat lung extract on mouse liver in two separate experiments. There was considerable batch variation in the control (buffer only) values attributable to differing maturity of animal groups. Only a slight increase in prolyl hydroxylase activity and collagen synthesis was found in animals treated with normal lung extract. A significant 2.6 fold rise in prolyl hydroxylase activity was evident after addition of paraquat lung extract. A similar 
Hepatic collagen prolyl hydroxylase activity and collagen chain synthesis (mean $\pm S E M$ ) in mice following intraperitoneal injection of lung extract

\begin{tabular}{lll}
\hline Substance injected & $\begin{array}{l}\text { Prolyl hydroxylase } \\
(D P M / 50 \mu l)\end{array}$ & $\begin{array}{l}\text { Collagen synthesis } \\
(D P M / 200 \mu l)\end{array}$ \\
\hline Buffer & $1167 \pm 208$ & $1326 \pm 365$ \\
Normal lung extract & $1306 \pm 194$ & $1460 \pm 1245$ \\
Buffer & $479 \pm 91$ & $381 \pm 269$ \\
Paraquat lung extract & $1238 \pm 111^{*}$ & $814 \pm 151$ \\
\hline
\end{tabular}

Two experiments were performed with groups of five and four mice.

${ }^{*} \mathrm{p}<0.01$ compared with buffer controls (Student's $t$ test).

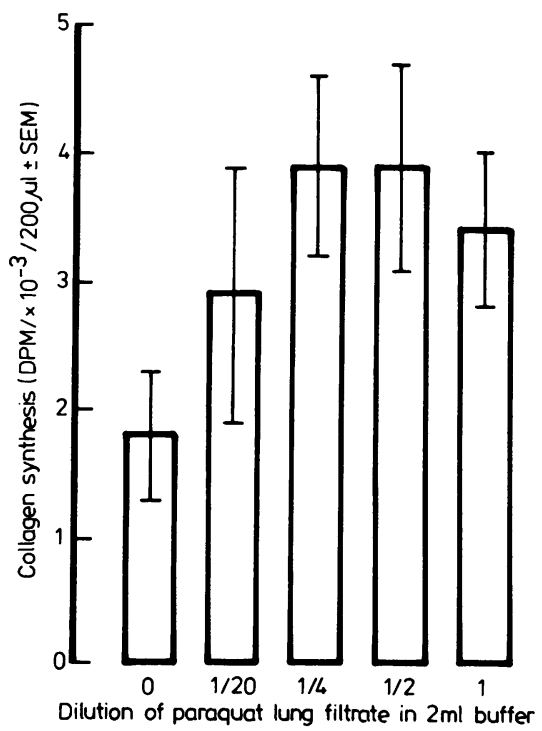

Fig. 7 Effect of injection of increasing amounts of paraquat lung extract on collagen synthesis in normal mouse liver. Increase in collagen synthesis becomes significant $(p<$ $0.05)$ at $1 / 4$ and 1/2 dilution with Student's t test.

rise was shown for collagen synthesis, but the result was not significant. Significant increases with the collagen synthesis assay were shown by the doseresponse experiment (Fig. 7) with paraquat lung extract, the value reaching a maximum of just over two fold.

\section{Discussion}

The pattern of five major zones of stimulating activity obtained from paraquat lung extracts resembles that previously seen with healing liver and skin material. $^{\prime 2}$ The inclusion of more control cultures than in previous work permitted statistical assessment and significance was achieved with the more sensitive and reliable assay for prolyl hydroxylase activity. Preparation of extracts after paraquat lung had been stored frozen resulted in the loss of activity from earlier column fractions and the appearance of residual activity in later fractions (Fig. 3,6) together with enhancement of the later protein peaks, particularly the last. This could well be attributable to the effect of proteolytic activity, and indeed collagen stimulating factors from liver have been shown previously to be trypsin sensitive..$^{12}$ The present findings suggest the possibility that the factors are not just finally degraded by proteolytic activity but are initially produced by it. Such a mechanism for increasing collagen synthesis would be consistent with the presence of large numbers of inflammatory cells in damaged tissue at this time. The presence and activity of macrophages have been shown to be of crucial importance in healing and fibrogenesis in wounds by Leibovich and Ross, ${ }^{13}$ and by us in carbon tetrachloride liver injury. ${ }^{10}$ The finding of collagen stimulating factors in this third type and site of tissue injury indicates that they are independent of the mode of injury and suggests that they are of general occurrence during recovery from injury and in all chronic inflammatory diseases.

The use of tissue culture fibroblasts as a model for detecting substances which enhance collagen production may seem appropriate, as collagen is the major synthetic product of the fibroblast. ${ }^{14}$ The rate of synthesis, however, varies considerably during different phases of culture growth, the rate of effective secretion increasing towards confluence, promoted by increasing prolyl hydroxylase activity. ${ }^{15} 16$ It is by no means clear which tissue culture conditions are analogous to cells in their natural environment. For example, platelet growth factor has been found to be ineffective in stimulating cell division when cells are cultured in flasks coated with extracellular matrix material. ${ }^{17}$ The question arises whether collagen stimulating factors, which are as yet uncharacterised, are merely a tissue culture artefact or whether they are truly operative in vivo.

Lung extracts were injected into mice intraperitoneally as this route can accept relatively large volumes and even large molecular weight materiał-for example, carrageenan ${ }^{18}$ - gains access to the circulation from this site. Membrane pore filtration rather than column chromatography was used since an overall effect as in vivo was sought. Similarly, the filtrates used contained material < 50000 daltons as compared with the column fractions $<5000$ daltons beyond the first peak. This was because initial fibroblast culture work with carbon tetrachloride injured liver filtrates had shown the 
greatest activity to reside in this filtrate and progressively less in filtrates of $<10000$ and $<5000$ daltons (unpublished data). The term "collagen stimulating factors" has been applied previously to material $<5000$ daltons but since they are uncharacterised and the term is non-specific, it seems fair to apply it to the larger molecular weight fractions also.

From the Table it is apparent that the filtrates are capable of stimulating collagen synthesis in vivo. The dose-response experiment (Fig. 7) shows that, given sufficient animals at each point, such increases can even be quantitated. The maximum of just over two fold stimulation reached as compared with up to five fold in cultures probably indicates just how non-optimal are tissue culture conditions. The fact that stimulation has been obtained in healthy mouse liver and also twice in lung (data not shown) using a rat lung extract emphasises that collagen stimulating factors are not organ or species specific. It is notable that in the paraquat treated rat itself, the lung being selectively damaged exhibits increased collagen synthesis in contrast to liver or kidney. ${ }^{5}$ The situation in the mouse is presumably one of unnatural systemic access of stimulating factors.

The evidence presented here is limited, but collagen stimulating factors appear to have the ability to override normal control mechanisms in vivo and this surely indicates a pathological importance.

We thank Mrs Lesley McColl for technical assistance. This work was supported by the Distiller's Company and funds of the University of Glasgow.

\section{References}

' McGee J O' D, O'Hare RP, Patrick RS. Stimulation of the collagen-biosynthetic pathway by factors isolated from experimentally-injured liver. Nature New Biol 1973;243: 121-3.

2 O' Hare RP, Fallon A, Bradley JF, Burns J, McGee J O' D. Isolation of collagen stimulating factors from healing wounds. $J$ Clin Pathol 1983;36:707-11.
${ }^{3}$ Smith $P$, Heath D. The ultrastructure and time sequence of the early stages of paraquat lung in rats. $J$ Pathol 1974;114:11783.

${ }^{4}$ Smith P, Heath D, Kay JM. The pathogenesis and structure of paraquat-induced pulmonary fibrosis in rats. $J$ Pathol 1974;114:57-67.

s Thompson WD, Patrick RS. Collagen prolyl hydroxylase levels in experimental paraquat poisoning. Br J Exp Pathol 1978;59:288-91.

- Cardinale GJ, Udenfriend S. Prolyl hydroxylase. Adv Enzymol 1974;41:245-300.

' Hutton JJ Jr, Tappel AL, Udenfriend S. A rapid assay for collagen proline hydroxylase. Anal Biochem 1966;16:384-94.

${ }^{8}$ Peterkofsky B, Diegelmann R. Use of a mixture of proteinasefree collagenases for the specific assay of radioactive collagen in the presence of other proteins. Biochemistry 1971;10:98894.

9 Patrick RS, Martin J, Thompson WD. The collagen prolyl hydroxylase activity of hepatocytes and mesenchymal cells isolated from normal and regenerating rat liver. Diagn Histopathol 1981;4:95-8.

${ }^{10}$ Thompson WD, Jack AS, Patrick RS. The possible role of macrophages in transient hepatic fibrogenesis induced by acute carbon tetrachloride injury. J Pathol 1980;130:65-73.

" Fallon A, Bradley JF, McGee J O'D. Collagen stimulating factors in hepatic fibrogenesis. J Clin Pathol 1984;37:542-8.

12 McGee J O'D, Fallon A. Hepatic cirrhosis-a collagen formative disease? J Clin Pathol 1978;31 (suppl 12):150-7.

${ }^{13}$ Leibovich SJ, Ross R. The role of the macrophage in wound repair: a study with hydrocortisone and antimacrophage serum. Am J Pathol 1975;78:71-100.

14 Grant ME, Prockop DJ. The biosynthesis of collagen. $N$ Engl J Med 1972;286:194-9, 242-9, 291-300.

15 Cardinale GJ, Stassen FLH, Kuttan R, Udenfriend S. Activation of prolyl hydroxylase in fibroblasts by ascorbic acid. Ann NY Acad Sci 1975;258:278-87.

${ }^{16}$ Blanck TJJ, Peterkofsky B. The stimulation of collagen secretion by ascorbate as a result of increased proline hydroxylation in chick embryo fibroblasts. Arch Biochem Biophys 1975; 171:259-67.

${ }^{17}$ Gospodarowicz D, Tauber J-P. Growth factors and the extracellular matrix. Endrocrine Rev 1980;1:201-7.

${ }^{18}$ Thomson AW, Fowler EF, Pugh-Humphreys RGP. Immunopharmacology of the macrophage-toxic agent carrageenan. Int J Immunopharmacol 1979;1:247-61.

Requests for reprints to: Dr WD Thompson, Department of Pathology, University Medical Buildings, Foresterhill, Aberdeen AB9 2ZD, Scotland. 